\title{
Publisher Correction: Polymorphic residues in rice NLRs expand binding and response to effectors of the blast pathogen
}

Juan Carlos De la Concepcion (1D, Marina Franceschetti (D), Abbas Maqbool (1), Hiromasa Saitoh (D), Ryohei Terauchi (D), Sophien Kamoun (1) and Mark J. Banfield (1)

Correction to: Nature Plants https://doi.org/10.1038/s41477-018-0194-x, published online 9 July 2018.

In the version of this Article originally published, in Fig. $1 \mathrm{~b}$ the single-letter code for the amino acid polymorphism at position 46 in the schematic of the AVR-PikE variant was incorrectly given as ' $\mathrm{H}$ '. The correct amino acid is ' $\mathrm{N}$ '. This has now been amended in all versions of the Article. 